RECIAL Vol. XII, № 19 RECHAL
ISSN 2718- 658X

Centro de Investigaciones Facultad de Filosofía y Humanidades de la Universidad Nacional de Córdoba,

Enero | Junio 2021 Córdoba, Argentina.

\title{
Una intimidad intermitente en Las mejores pérdidas
}

Vargas, S. (2020). Las mejores pérdidas (138 pp.). Río Cuarto: Cartografías.

Natalia Lorio*

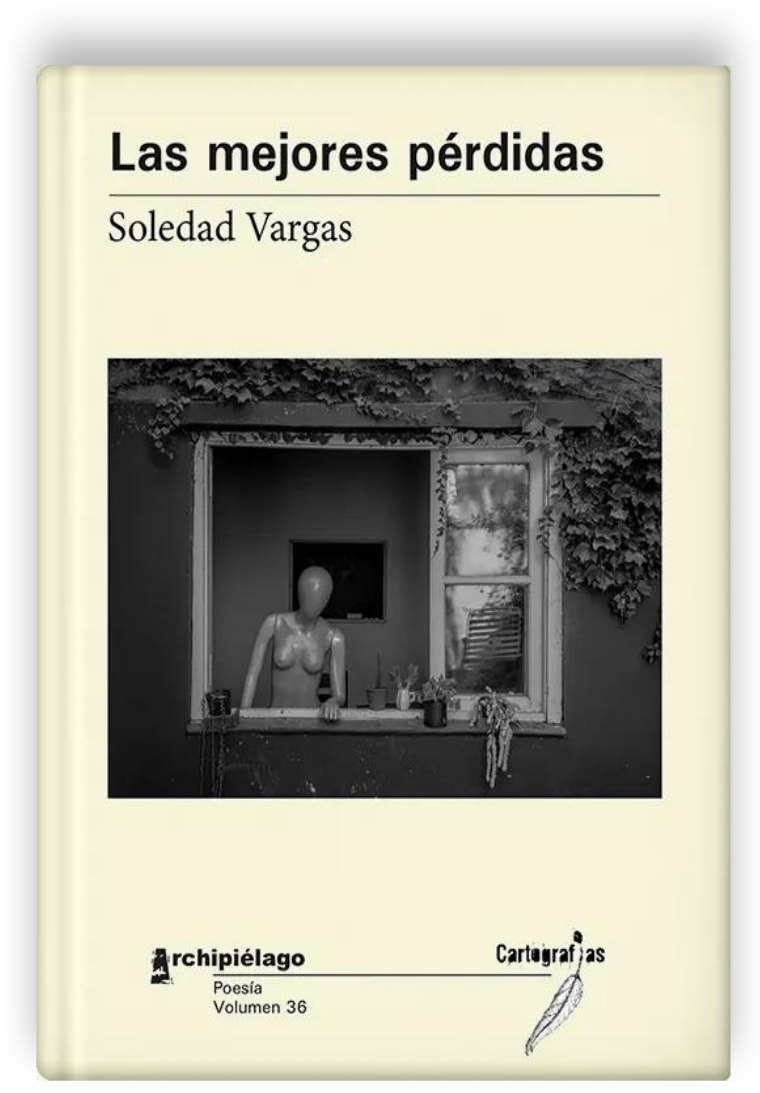

Hay una definición de la telepatía que dice que es la coincidencia de pensamientos o sensaciones sin el concurso de los sentidos. Hay otra, que me gusta más, que la define como un modo de comunicación de la experiencia, de transmisión (desde lejos, a lo lejos) de lo que padecemos (pathos). Me quedo con esta formulación de la telepatía, la de una comunicación, la de una transmisión, no de lo mismo, sino de algo distinto.

\footnotetext{
* Doctora en Filosofía por la Universidad Nacional de Córdoba, profesora asistente en la Escuela de Filosofía, Facultad de Filosofía y Humanidades, Universidad Nacional de Córdoba, Argentina. nalorio@unc.edu.ar.

Recibido 30/04/2021. Aceptado 20/05/2021.
} 
Desde ahí, la telepatía no podría ser constante, continua, plena, sino algo que comunica, pero desde la intermitencia, desde la pérdida de lo pleno: telepatía de algo que nos llega de a saltos (como contagios de experiencia o transferencia diferida de experiencias; así creo que aparece la idea de telepatía en la película Despertando a la vida, de Richard Linklater) o con interrupciones, o intermitencia (como lo muestra toda la saga de las películas de mutantes en las que, de paso, se nos dice que la telepatía continua, constante e inmediata se parece bastante al infierno del cerebro. Ahí entonces, una pérdida de la señal, una pérdida de la comunicación de la experiencia puede ser una buena pérdida).

Es François Jullien quien indica que lo íntimo remite a lo profundo, lo apartado y oculto, pero también a la relación. Asimismo, remite a la intensificación o la radicalización de un interior, pero también a su contrario, a la unión con otro, la apertura a otro (Jullien, 2016, p. 19). Lo íntimo se comunica en el fondo con su opuesto. Lo retirado de lo íntimo es también lo que puede exponerse y salir así de la neutralidad y la indiferencia. El registro de lo íntimo es expresado por Jullien (2016) como "apertura al exterior inscrita en el seno de la profundización del interior" (p. 24). Ese registro de lo íntimo es el que encontramos en este libro de poesía: la interioridad y la exterioridad están superpuestas, a-postándose, en un juego de postas que no resuelve ni por la opacidad absoluta y ni por la transparencia nítida de un yo, sino por ser ocasión para el cauce de lo íntimo en la escritura ¿Cómo no ver allí los rastros, las huellas de algunos lazos expuestos?, ¿cómo no reconocer lo velado y las relaciones o lazos posibles con otros, incluso, una llamada, un puente? Decimos, entonces, que hay una intimidad que no es la de la soledad, sino la de un llamado, la de una comunicación posible desde un poema: "te llamo desde este poema/ ese tiempo/en que nadie sabe/en qué lugar de su vida está".

Esta no es una intimidad inofensiva - tal como propone Tamara Kamenszain (2016) para leer toda una serie de poéticas contemporáneas-, sino más bien una intimidad atravesada por el cuerpo, por el cuerpo de lo erótico, por el cuerpo que es garganta, por el cuerpo que resiste, que desea y también por el cuerpo que usamos para enfermar. Una intimidad material del cuerpo que se hace gesto, una intimidad que está atravesada por la pérdida, pero una pérdida que no es la de la derrota. Esa ausencia de derrotismo, incluso de pesimismos, abre a preguntarse por las mejores pérdidas: ¿dónde empiezan y terminan vida y pérdida, vida y despedida? "Hay una parte de la despedida donde ya no te ven, al gesto lo hacés sola", así comienza este libro en el que parece que se cruzan vidas y pérdidas, idas y despedidas. Y, sin embargo, un tendón impulsa a hacer algo con el dolor, no desde el derrotismo - insisto- - pero tampoco desde su negación (toda vez que se presenta el dolor como oportunidad para una supuesta ganancia, como si la única esperanza fuera empaquetarse en una subjetividad empresarial que tiene como dictum que "con todo hay que saber-hacer"). No. Si "Con el dolor/ hay que poder/hacer algo/más/que un cáncer”, esa exigencia es más bien poder hacer algo, incluso poder perder. Poder perder, hacer lo mejor para poder perder: escribir, sentir, despedir, amar, desear, reír. Vivir puede ser la mejor pérdida.

El gesto poético de Soledad Vargas despeja cualquier nostalgia del pasado (por lo que fue, por el amor y sus gestos cómplices, por lo tenido) con la certeza de un deseo de otra cosa, con la perplejidad de algo que se parece más a una nostalgia por adelantado que se pregunta:

¿Siempre va a ser así?/ ¿así cómo?/ ¿así de lo mismo?/¿así de piel?/¿es mucho?/ no no no/ Te pregunto/ si siempre vamos a sentir tanto/ah, 
todavía no sé del futuro/De hecho, hoy/ escribo desde ahí/ ya no estás/ya no es así/ y el mundo tiene la insoportable ambigüedad/de los recuerdos.

O que apuesta a "aprender a estar en silencio/ con las tripas a los gritos", una apuesta por un tipo de vida sensible, atravesada por la pérdida que la constituye, pero que puede despedir, despedirse, que puede abrigar sentir lo que aún no sucedió o que puede "hacer una pausa para lo que acaba de nacer". Que puede tramar una vida y sus pérdidas desde el haz del cuidado: cuidar lo que nace y cuidar lo que muere, cuidar lo que (se) mueve.

En el título de este libro, "Las mejores pérdidas", hay un guiño, un chiste, una señal telepática. ¿Qué pérdidas pueden ser las mejores? Quizá para quien apuesta en un juego, apostar (y perder) puede ser una de las mejores pérdidas. Y si es cierto que solo podemos amar lo que no dura, ¿el amor podría ser una de las mejores pérdidas? "Como si el amor fuera eso que es cierto" dice Soledad Vargas o el amor como un juego perdido (o como la canción de Amy Winehouse, "Love is a losing game"). O como aparece en otro poema de este libro: "lo erótico se desgarra con los dientes/como si pudiésemos/ tragar el montón de vida/ que nos permite/ morir y nacer en el mismo cuerpo".

Pero también podríamos pensar esa intimidad no inofensiva, en la que la decisión de la despedida es parte de la resistencia (¿o denuncia?) de las formas del amor de las que venimos... y aun una suerte de decisión de exiliarse del amor del que venimos, exiliarse de los modos que reaseguran pasiones tristes:

Exiliarse con belleza/como una estación de meses/ o de trenes/de a poquito y sin rieles/ Exiliarse del exceso de yo/o de vos,/ y escribir sobre el paisaje/que te encuentra en la ventana/En caso de emergencia, /rompa el vidrio/de una buena vez, rómpalo/En caso de exilio/ vuelva al detalle.

En estos sentidos, no creo que aquí se trate de una intimidad inofensiva, como tampoco de una escritura militante, de denuncia, sino de una escritura de la intimidad que muy lúcida y sensiblemente se sabe atravesada por el límite y la pérdida, por cierto exilio del yo, pero que sabe volver a él (a ese yo) como una guarida, para juntar signos y volver a salir. Así, el orden de lo íntimo presentado en estos términos es cómplice de una experiencia, que trenza saber, gestos, resistencias, voces, cuerpos, pero no para ganarlos y apropiarse, sino para también hacer experiencia de su negación - ese juego que permite la escritura-, allí donde la pérdida puede escribirse ("No hay/ no queda/no llegó/no mandaron/ no tenemos/cama/quirófano/cara/alguna novedad / está todo quieto/ me duele") un No que es el que inscribe una ruptura, que puede ver lo quebrado, que si denuncia algo es que la negación puede sonar como un grito que suspende la aparente inofensividad de una pérdida, ... y (a los gritos) poder resistir. En el poema dedicado a Ana Iliovich se lee: "escucha los pájaros/que resisten en el Campo/le recuerdan que nunca estuvo sola/ que ninguna garganta se queda sola/cuando aún resta/ aire de grito".

Entre las formas y gestos que se recuperan está la amistad, ese exilio del amor figurado de un modo posesivo que insiste en la posibilidad de recordar otro gesto, quizá el de la transmutación del amor en otra cosa, o la interrupción de cierta forma del amor propuesta desde la amistad: 
Me recuerda que aunque no/ que aunque no/ que aunque de nuevo no/hay la amistad/ que te pone anteojos /y te pregunta: ¿qué esperabas ver?/ ¿El amor?/ ¿Para qué?/ Yo te presento el mundo/ y me quedo aquí cerca/ por si te dan ganas de decir algo.

Por último, quizá no es insensato apostar por la suerte que liga telepatía y poesía, y es posible afirmar que la poesía es un ejercicio de telepatía: un poder intermitente de comunicar lucidez sensible, experiencia, poder dar algo adivinado, intuido, aprendido, sufrido, gozado. La poesía como el ejercicio intermitente de poder perder.

\section{Referencias}

Jullien, F. (2016). Lo íntimo. Lejos del ruidoso amor. Buenos Aires: Cuenco de plata. Kamenszain, T. (2016). Una intimidad inofensiva. Los que escriben con lo que hay. Buenos Aires: Eterna Cadencia. 